\title{
Valor Econômico para Componentes do Leite no Estado do Rio Grande do Sul ${ }^{1}$ \\ Pedro Renan de Barros Bueno², Paulo Roberto Nogara Rorato ${ }^{3}$, João Walter Dürr ${ }^{4}$, Ernesto Enio Budke Krug ${ }^{5}$
}

\begin{abstract}
RESUMO - Com o objetivo de estudar a influência do fator econômico sobre os objetivos de seleção dos animais, foram utilizados dados de produção de um programa de pagamento por qualidade de leite implantado por uma empresa laticinista do estado do Rio Grande do Sul. Os critérios de qualidade do referido programa constavam de teores mínimos de 3,1\% de gordura, 2,85\% de proteína e no máximo 500.000 unidades de células somáticas. Os dados foram estratificados em três níveis, de acordo com o volume de leite entregue, mensalmente, para a indústria, em função de diferenças significativas em relação aos custos de produção, por litro de leite, decorrentes da escala de produção das propriedades. No nível 1, foram agrupadas as produções das propriedades que entregavam até 1.500 litros de leite/mês, no nível 2, as produções entre 1.501 e 3.000 litros de leite/mês e no nível 3, as produções acima de 3.000 litros de leite/ mês. As receitas dos componentes por litro de leite variaram em função da bonificação pelo volume de leite entregue, obtendo maiores valores quanto maior o volume. As despesas definiram o valor econômico para os componentes do leite, em que os custos de produção nos diferentes níveis geraram diferentes funções de lucro. Os valores econômicos (R \$) para os componentes foram de $-0,4290 ;-0,1906$ e - 0,3772 e de -0,0624; 0,0836 e -0,0193 para a gordura e a proteína, respectivamente, nos níveis 1,2 e 3 . O veículo apresentou valor econômico sempre positivo e mais alto que os outros componentes, 0,1964; 0,2093 e 0,2210 para os níveis 1, 2 e 3, respectivamente.
\end{abstract}

Palavras-chave: custo de produção, função de lucro, objetivo de seleção, qualidade do leite

\section{Economic Value for Milk Components in the State of Rio Grande do Sul, Brazil}

\begin{abstract}
In order to study the influence of the economic factor on the objectives used to select the animals, production data of a payment program by milk quality implanted by a milk industry of Rio Grande do Sul were used. The criteria of quality of the referred program consisted of minimum contents of $3.1 \%$ of fat, $2.85 \%$ of protein and a maximum 500,000 units of somatic cells. The data were stratified in three levels, in agreement with the volume of milk received monthly by the industry from the properties, due to significant differences in relation to the production costs by liters of milk, resulting from the production capacity of the properties. Level 1 included the production of the properties that delivered up to 1,500 liters of milk for month, Level 2, the production between 1,501 and 3,000 liters and Level 3, the ones that delivered above 3,000 liters. The revenues of the components by liter of milk varied due to the allowance received for the volume of milk delivered, obtaining higher values for larger volume. The expenses led to the economic value (R\$) for the milk components where production costs in different levels generate different functions of the income. The economic values for the components were of $-0.4290 ;-0.1906$ and -0.3772 for fat, $-0.0624 ; 0.0836$ and -0.0193 for protein, at levels 1,2 and 3 respectively; the carrier always presented positive economic value. Also, these values where higher than the other components, showing values 0.1964 ; 0.2093 and 0.2210 at Levels 1, 2 and 3 respectively.
\end{abstract}

Key Words: production cost, profit function, selection objective, milk quality

\section{Introdução}

O aumento da produção de leite ocorrida no país, na segunda metade da década de 90 , é decorrente, principalmente, do aumento do rebanho (Embrapa, 2001a) e não da melhoria das condições de produção ou tecnificação dos produtores (Konzen, 1998).

Considerando a produção de leite por vaca/ano como índice de nível tecnológico, os Estados Unidos, com produção de 7.953 litros de leite por vaca/ano, estão classificados como primeiro e o Brasil, com produção de 1.154 litros vaca/ano, como 16o colocado (Embrapa, 2001b). Esta disparidade técnica entre os dois países nos dá a certeza da necessidade de buscar melhores índices para a produção leiteira brasileira. O Estado do Rio Grande do Sul, com produção de 1.768 litros de leite por vaca/ano, detém o melhor índice no país, porém bem inferior ao obtido pelos Estados Unidos.

\footnotetext{
1 Parte da Dissertação de Mestrado apresentada à UFSM pelo primeiro autor.

${ }^{2}$ Méd. Veterinário, Aluno de Mestrado em Zootecnia da UFSM, Bolsista - CNPq (pedrorbb@bol.com.br).

3 Professor Adjunto do Dep. Zootecnia da UFSM (rorato@smail.ufsm.br).

${ }^{4}$ Professor da UPF (durr@upf.tche.br).

5 Professor da UPF (ekrug@elege.com.br).
} 
O melhoramento do rebanho leiteiro brasileiro, de raças européias, ainda está condicionado a estudos realizados em países com alta tecnologia, os quais são nossos fornecedores de material genético. A disseminação desse material genético avaliado em outras condições ambientais pode não corresponder aos ganhos esperados, em razão da interação genótipoambiente (Rorato et al., 1999). A eficiência econômica de um programa de melhoramento genético depende da adequada determinação dos objetivos de seleção, que deve ser baseada nas características que irão influenciar no desempenho econômico da produção (Pearson \& Miller, 1981).

Dürr \& Rorato (2000) salientam que a tendência genética preconizada no país, em relação à qualidade do leite, deve seguir aquela observada nos países grandes produtores, visando o mercado consumidor.

Para que a atividade primária, produção de leite, seja eficiente com relação à expectativa da indústria, esta deverá orientar a cadeia produtiva (Dekkers \& Gibson, 1998), pois é na indústria que se reflete a demanda de consumo dos produtos industrializados a partir do leite. Segundo Buzinhani (1998), a indústria laticinista depende diretamente do conteúdo de proteína e sua composição, onde a caseína, que representa $80 \%$ das proteínas do leite, é fator primordial para a produção de queijo, um dos principais produtos industrializados a partir do leite.

O precursor em trabalhos que consideram a parte econômica no melhoramento animal foi Hazel (1943), que definiu o objetivo de seleção como uma função linear dos valores genéticos para cada característica (genótipo agregado) ponderado pela sua importância econômica relativa (valor econômico). Ficou definido por este autor que o valor econômico é a quantidade de aumento no lucro, proporcionado pelo acréscimo de uma unidade de melhoria na característica em questão, mantendo as outras constantes.

$\mathrm{Na}$ análise econômica da produção de leite, a função de lucro relaciona a receita oriunda da produção com os respectivos custos envolvidos, podendo ser representada da seguinte forma:

$$
\mathrm{L}=\mathrm{R}-\mathrm{C}_{(1)}
$$

em que $\mathrm{L}=$ lucro, $\mathrm{R}=$ receita e $\mathrm{C}=$ custo.

As análises por intermédio das equações de lucro refletem a sensibilidade dos valores econômicos das características para mudanças em preço e circuns- tâncias de produção, mostrando que os valores econômicos podem mudar dependendo do nível de produção e dos preços praticados (Bekman \& Van Arendonk, 1993).

Smith et al. (1963) propuseram duas condições para se calcular pesos econômicos a partir de funções de lucro: a primeira, que qualquer mudança no lucro alcançada pela correção de ineficiência no sistema de produção não deveria ser considerada e a segunda, que qualquer lucro extra obtido pelo reescalonamento do tamanho da empresa, sem alteração genética, também não deve ser adotado. Constataram, portanto, que o verdadeiro lucro é obtido por redução nos custos de produção por unidade de valor do produto e aumento da receita pela melhoria da qualidade do produto.

Nesta última década, a indústria laticinista brasileira sofreu importantes alterações na sua estrutura administrativa, decorrência direta da abertura do mercado internacional para comercialização de produtos agropecuários, buscando tornar-se competitiva na conquista do mercado consumidor.

Segundo Madalena (1999b), vários autores têm salientado que o sistema de pagamento pela composição do leite constitui uma poderosa ferramenta para direcionar mudanças genéticas. $\mathrm{O}$ fato de $\mathrm{o}$ sistema de pagamento do leite em algumas regiões do Brasil remunerar pouco ou negativamente a proteína e a gordura, resultando em pesos econômicos negativos, ou muito baixos para esses dois componentes, faz com que os índices de seleção daí decorrentes priorizem o veículo (leite sem gordura e sem proteína), ao contrário da tendência mundial. Dessa forma, a seleção com base nos valores econômicos atuais dessas regiões reduziria os teores desses componentes, de maneira que no futuro o rebanho poderia ficar menos rentável, caso os valores mundiais viessem a vigorar também no Brasil.

No Brasil, os programas ditos "pagamento por qualidade" geralmente incluem uma série de fatores relacionados com as condições de produção, que, embora sejam importantes para a atividade leiteira, não medem a qualidade do leite em si (Madalena, 1999a). Os diferentes sistemas de pagamento, em operação nas diferentes regiões da Austrália, são uma das principais fontes de variação do peso econômico dos componentes do leite (Bowman, 1996).

Os preços de insumos e fatores de produção são muito importantes na determinação dos valores econômicos para diferentes características dentro das 
propriedades (Gröen, 1989), da mesma forma que as informações sobre peso vivo e ingestão de alimentos quando da seleção para eficiência econômica em gado de leite (Veercamp, 1998). Alterações nos preços dos insumos revelam que os produtores de leite são sensíveis às variáveis de preços destes insumos, visto que reduzem a produção, quando ocorre aumento do preço dos fatores capital, mão-de-obra e alimentação (Gurgel, 2000). Entretanto, os produtores que se antecipam na inovação tecnológica e na expansão dos empreendimentos, com redução dos custos, tendem a elevar seus ganhos obtendo maior margem de retorno do capital investido (Konzen, 1998).

O nível tecnológico, caracterizado por produção de leite/vaca/ano, é um fator importante no retorno econômico da produção leiteira e este está diretamente relacionado ao sistema de produção.

Konzen (1998), a partir dos resultados dos custos dos sistemas de produção, constatou que os sistemas mais tecnificados na produção de leite são mais rentáveis que os de nível tecnológico inferior. Da mesma forma, Mancio et al. (1999), avaliando os índices zootécnicos, custos de produção e a rentabilidade de quatro empresas de produção de leite tipo B, no Estado de São Paulo, no período de maio de 1995 a abril de 1996, observaram que a alta produtividade significou maior benefício econômico.

Entretanto, Holanda Jr. \& Madalena (1998), analisando a rentabilidade de diferentes sistemas de produção de leite na região Sudeste e em cenário de preço padronizado, observaram que os sistemas menos intensificados, em geral, tiveram rentabilidade bem maior que os sistemas mais intensificados. As características diferenciadas para o grupo mais rentável foram: baixo custo operacional, uso de gado mestiço e menor capital investido por litro de leite. Da mesma forma, Vilela et al. (1996), comparando a produção de vacas da raça Holandesa em pastagem de coastcross e em confinamento total, na região sudeste, relataram que, apesar de os animais confinados produzirem mais $(20,6 \mathrm{~kg}$ de leite em média) que animais em pastejo $(16,6 \mathrm{~kg}$ de leite em média), o primeiro grupo apresentou um custo operacional por animal muito superior (US\$ 809,00 vs. US\$ 352,12), o que compensava a menor produção de leite a pasto. Assim, as relações encontradas sugerem que existem limites para as despesas com concentrados e benfeitorias acima dos quais o retorno não é compensador, em razão de o preço pago pelo litro de leite nessas regiões não cobrir os custos adicionais, impedindo a intensificação da atividade.

\section{Material e Métodos}

Os dados para o desenvolvimento deste trabalho são oriundos dos arquivos do Serviço de Análise de Rebanhos Leiteiros (SARLE) da Universidade de Passo Fundo, sediada no município de Passo Fundo, no Estado do Rio Grande do Sul. Estes registros fazem parte do programa de "Controle de Qualidade do Leite" implantado por uma empresa laticinista do Rio Grande do Sul, a qual possui postos de coleta e de resfriamento distribuídos por diversos municípios do estado. Dessa forma, considerou-se que este banco de dados seja representativo do rebanho leiteiro do estado do Rio Grande do Sul, que é composto, em sua maioria, por vacas da raça Holandesa e suas cruzas.

Os registros de qualidade do leite foram utilizados como um dos critérios de pagamento ao produtor pela empresa, caracterizando a preocupação com a origem e qualidade do produto a ser utilizado na indústria laticinista. O arquivo original continha 135.153 registros de produção de leite, oriundos de 5.122 propriedades rurais, distribuídas em 11 regiões, subdivididas em 109 rotas, cada rota correspondendo a um trajeto de coleta de leite pelo caminhão-tanque. Do arquivo original, foram eliminados registros incompletos, considerando-se somente os registros que possuíam as informações de produção e de qualidade da respectiva propriedade. Os dados de qualidade do leite compunham um arquivo de 46.440 amostras coletadas durante o período do mês de maio de 1998 a abril de 2001.

Com o objetivo de obter-se maior confiabilidade dos dados, eliminou-se os registros de porcentagem de gordura $(\% \mathrm{G})$ e de proteína $(\% \mathrm{P})$, acima e abaixo de dois desvios-padrão em relação à média para esses componentes. A formação do arquivo e a edição dos dados foram efetuadas com a utilização do pacote estatístico SAS (SAS, 1996), versão 6.11 para microcomputadores.

Para eliminar o efeito de escala de produção, os dados foram estratificados em três níveis de produção, tendo como base a produção mensal de leite coletada a granel com o caminhão-tanque na unidade produtora. Foram agrupados no nível 1 as propriedades que entregaram até 1.500 litros de leite/mês; no nível 2, as propriedades que entregaram de 1.501 a 3.000 litros de leite/mês; e no nível 3, as que entregaram mais que 3.000 litros de leite/mês. Segundo Krug (2001), no ano de 2000, dos produtores de leite vinculados a 23 Cooperativas e uma empresa laticinista do Rio Grande 
do Sul, a proporção de produtores que se enquadravam nestes níveis era de 48,42; 28,31 e 23,27\% para os níveis 1,2 e 3 , respectivamente.

Os valores médios estimados para as características estudadas, de acordo com os diferentes níveis de produção, foram utilizados na determinação de receita e custo para cada componente (Tabela 1).

O estudo econômico baseia-se em informações obtidas em planilhas de custo de produção e de preços pagos ao produtor pela empresa laticinista do Rio Grande do Sul, por intermédio do seu Programa de Pagamento pela Qualidade. O programa considera os critérios de qualidade exigidos pela legislação em vigor, que consistem em teores mínimos de $3,1 \%$ de gordura e de $2,85 \%$ de proteína, além de contagem máxima de 500.000 unidades de células somáticas.

Foram calculados valores econômicos para os componentes do leite a partir das receitas geradas por cada um desses componentes e de seus respectivos custos de produção, como se descreve a seguir, partindo do princípio de que não há restrições, por cotas.

Os valores econômicos das características $\left(\mathrm{X}_{\mathrm{j}}\right)$ foram obtidos a partir de funções de lucro $\left(L=R_{j}-C_{j}\right)$ decorrentes das receitas $\left(R_{j}\right)$ e dos custos $\left(C_{j}\right)$ com elas associados, pela derivada parcial do lucro (L) com respeito a cada característica, avaliada na média de todas as outras características, segundo metodologia de Moav \& Hill (1966):

$$
\mathrm{v}_{\mathrm{k}}=\partial \mathrm{L} / \partial \mathrm{X}_{\mathrm{k}}
$$

Tabela 1- Valores estimados para análise geral e dentro dos níveis de produção, com respectivo número de amostras, médias de produção de leite (litros/mês), porcentagens de gordura (\%G) e de proteína (\%P)

Table 1 - Estimated values by general analysis and by production levels, with respective number of samples, averages of milk production (liters/ month), fat ( $\% F)$ and protein $(\% P)$ percentages

\begin{tabular}{|c|c|c|c|c|}
\hline & $\begin{array}{c}\text { Geral } \\
\text { General }\end{array}$ & $\begin{array}{l}\text { Nível } 1 \\
\text { Level } 1\end{array}$ & $\begin{array}{l}\text { Nível } 2 \\
\text { Level } 2\end{array}$ & $\begin{array}{l}\text { Nível } 3 \\
\text { Level } 3\end{array}$ \\
\hline $\begin{array}{l}\text { № de amostras } \\
N \text {. of samples }\end{array}$ & 41.627 & 20.004 & 12.557 & 9.066 \\
\hline $\begin{array}{l}\text { Produção } \\
\text { (L/mês) } \\
\text { Production } \\
\text { (L/month) }\end{array}$ & 2.720 & 887,51 & $2.114,52$ & $7.602,86$ \\
\hline$\% \mathrm{G}$ & 3,53 & 3,51 & $\begin{array}{l}3,55 \\
3,10\end{array}$ & $\begin{array}{l}3,56 \\
3,10\end{array}$ \\
\hline
\end{tabular}

em que $X_{j}=m, j \neq k$ (2).

Para avaliar os valores $v_{j}$ aplicando a expressão $\mathrm{v}_{\mathrm{k}}$, foram utilizados preços e custos para cada componente, simulando situações relevantes no Rio Grande do Sul. Sendo $X_{j}=$ G, P ou V, em que a função de lucro por litro de leite pode ser expressa como:

$$
\mathrm{L}=\mathrm{S}_{\mathrm{j}}{ }^{3} \mathrm{X}_{\mathrm{j}}\left(\mathrm{p}_{\mathrm{j}}-\mathrm{ca} \mathrm{a}_{\mathrm{j}}\right)+\mathrm{f}(3)
$$

em que $\mathrm{p}=$ preço pago por unidade da característica e ca = custo de produção por unidade da característica, em moeda corrente, o subscrito j se refere a cada um dos três componentes e f corresponde a receitas e custos associados a outras características.

No pagamento mensal ao produtor, eram acrescidas as bonificações do Programa de Pagamento por Qualidade, ao preço do leite base (PLB), quando este cumprisse os critérios de qualidade especificados no programa. O preço médio do PLB recebido pelos produtores no período estudado foi de $\mathrm{R} \$ 0,20 / \mathrm{L}$, este mesmo valor foi pago pelo litro de leite que não possuía os teores mínimos de qualidade. Este valor poderia ser acrescido de bonificações, caso o produtor cumprisse com as exigências do programa, como por exemplo: para o critério de sanidade (atestados negativos para brucelose e tuberculose), o produtor teria aumento de $6 \%$ (de $\mathrm{R} \$ 0,20$ ) por litro de leite $\mathrm{e}$ para o nível tecnológico (possuir na propriedade tanque de resfriamento e inseminação artificial), incremento de $1 \%$ (de R $\$ 0,20$ ) somado ao valor base. Independentemente dos critérios de qualidade, os produtores recebiam bonificação pelo volume de leite, sendo fixados os percentuais de 2,4 e $12 \%$, dentro dos respectivos níveis de produção, acrescidos ao preço base por litro de leite. Os critérios de qualidade foram considerados como constantes durante o período de análise. Para obter o valor econômico dos componentes do leite para esta forma de pagamento, primeiramente, determinaram-se os teores de cada componente na composição do leite.

$\mathrm{O}$ custo de produção por unidade de produto, neste caso um litro de leite, foi estimado pelas equações de regressão, específicas para cada nível de produção. As equações foram obtidas a partir de planilhas de "custo de produção" de diversas propriedades produtoras, vinculadas à empresa que forneceu o programa de "Pagamento por Qualidade". As planilhas continham discriminados os elementos componentes dos custos fixos e dos variáveis, sendo os fixos definidos como custos não desembolsáveis, 
dentre eles a depreciação de benfeitorias, máquinas e equipamentos, além das pastagens perenes. Entre os variáveis, os custos com alimentação (pastagens anuais, concentrados e silagens), sanidade, transporte, inseminação, energia, mão-de-obra, manutenção de benfeitorias, máquinas, equipamentos e impostos.

$\mathrm{Na}$ Tabela 2, estão expressos o número de planilhas utilizadas para cada nível de produção, as equações de regressão resultantes e os respectivos coeficientes de determinação $\left(\mathrm{R}^{2}\right)$.

A produção de leite anual precisou ser estimada a partir da produção média mensal, em razão da falta de registros de algumas propriedades em determinados meses.

A partir dos custos variáveis estimados, por meio das equações de regressão para cada nível de produção, determinou-se o custo de produção para cada um dos componentes do leite, com base na proporção dos requerimentos calóricos para síntese dos mesmos, definidos pelo NRC (2001).

Para retirar o efeito do custo de manutenção da vaca, da função de lucro das características, determinou-se a parcela do custo variável destinada a manutenção da vaca, considerando que este custo seja independente do custo de produção dos componentes do leite. Foi necessário estimar, por intermédio de equações de regressão, o número médio de vacas em lactação dentro dos respectivos níveis de produção (Tabela 3 ).

Foi estipulado um peso vivo (pv) médio de $450 \mathrm{~kg}$ para as vacas em lactação em todos os níveis de produção.

Tabela 2 - Número de planilhas (N) utilizadas para determinação da equação de regressão de custos variáveis, em reais $(R \$)$, equação de regressão, coeficientes de determinação $\left(R^{2}\right)$ e de variação $(C V)$, para os diferentes níveis de produção

Table 2 - Number of spreedsheets $(N)$ used for determination of the equation of regression of variables costs $(R \$)$, regression equation, determination $\left(R^{2}\right)$ and variation coefficients $(\mathrm{CV})$, for the different production levels

\begin{tabular}{lcccc}
\hline $\begin{array}{l}\text { Níveis } \\
\text { Levels }\end{array}$ & $\mathrm{N}$ & $\begin{array}{l}\text { Regressão } \\
\text { Regression }\end{array}$ & $\mathrm{R}^{2}$ & $\mathrm{CV}$ \\
\hline 1 & 3 & $37,005495+0,170639 \mathrm{X}$ & 95,32 & 3,71 \\
2 & 4 & $-1921,190146+0,178439 \mathrm{X}$ & 87,28 & 21,42 \\
3 & 15 & $-16203,000000+0,288397 \mathrm{X}$ & 98,74 & 8,14 \\
\hline
\end{tabular}

$\mathrm{X}=$ produção diária de leite da fazenda $(X=$ milk production/farm/day).

$$
\mathrm{EL}_{\mathrm{m}}=0,08 * \mathrm{pv}^{0,75}
$$

em que $\mathrm{EL}_{\mathrm{m}}=$ energia líquida para manutenção; $\mathrm{pv}=$ peso vivo da vaca em lactação

Os requerimentos calóricos para produção de leite e de seus componentes seguem a seguinte proporção, segundo a equação proposta pelo NRC (2001):

$$
\begin{gathered}
\mathrm{EL}_{\text {Leite }}=(0,0929 * \% \mathrm{G})+(0,0547 * \% \mathrm{P})+ \\
(0,0395 * \% \mathrm{~L})_{(5)}
\end{gathered}
$$

A porcentagem de lactose foi definida como constante, com valor médio de 4,63\% na composição do leite, conforme informe pessoal de Dürr (2001), baseado em resultados de análises de amostras de leite realizadas no SARLE. O somatório da porcentagens de lactose e de água mais os minerais foi definido como veículo (leite sem gordura e sem proteína).

Os custos variáveis (alimentação, sanidade e manutenção de instalações e equipamentos) foram rateados entre mantença da vaca em lactação e produções de gordura a $3,1 \%\left(\% \mathrm{G}_{3,1}\right)$, gordura acima de $3,1 \%\left(\% \mathrm{G}_{>3,1}\right)$, proteína a $2,85 \%\left(\% \mathrm{P}_{3,1}\right)$, proteína acima de $2,85 \%\left(\% \mathrm{P}_{>3,1}\right)$ e veículo $(\mathrm{V})$, com base nos requerimentos energéticos para o metabolismo de cada componente, conforme Tabela 4.

Neste trabalho, objetivou-se calcular os pesos econômicos dos diferentes componentes do leite, de importância econômica, dentro de diferentes níveis

Tabela 3 - Número de propriedades (N) utilizadas para determinação da equação de regressão de número de vacas em lactação, equação de regressão, respectivo coeficiente de determinação $\left(R^{2}\right)$ e coeficiente de variação $(C V)$, para os diferentes níveis de produção

Table 3 - Number of properties $(N)$ used for determination of the regression equation for number of milking cows, regression equation, determination $\left(R^{2}\right)$ and coefficients of variation $(\mathrm{CV})$, for the different production levels

\begin{tabular}{lcccc}
\hline $\begin{array}{l}\text { Níveis } \\
\text { Levels }\end{array}$ & $\mathrm{N}$ & $\begin{array}{l}\text { Regressão } \\
\text { Regression }\end{array}$ & $\mathrm{R}^{2}$ & $\mathrm{CV}$ \\
\hline 1 & 2.416 & $2,148645+0,087856 \mathrm{X}$ & 34,79 & 32,73 \\
2 & 863 & $3,387209+0,067327 \mathrm{X}$ & 12,79 & 30,07 \\
3 & 643 & $6,234523+0,051755 \mathrm{X}$ & 79,72 & 39,28 \\
\hline
\end{tabular}

$\mathrm{X}=$ produção diária de leite da fazenda $(X=$ milk production/farm/day $)$. 
Tabela 4 - Porcentagem dos componentes no leite, necessidade de calorias para manutenção e produção dos componentes em mega-calorias (Mcal), e porcentagem de energia destinada aos componentes, em relação à produção de leite/ano $(\mathrm{PL})$ e ao número estimado (№) de vacas em lactação

Table 4 - Percentage of the components in the milk, amount of calories needed for maintenance and production of the components in mega-calories (Mcal), and percentage of energy destined to the components, in relation to to milk/production/year (MP) and the estimated number (N.) of milking cows

\begin{tabular}{|c|c|c|c|c|c|c|c|c|c|}
\hline \multirow{4}{*}{$\begin{array}{l}\text { №/vacas } \\
\text { N./cows } \\
\text { PL/ano } \\
\text { MP/year }\end{array}$} & \multicolumn{3}{|c|}{$\begin{array}{l}\text { Nível } 1 \\
\text { Level } 1 \\
\end{array}$} & \multicolumn{3}{|c|}{$\begin{array}{l}\text { Nível } 2 \\
\text { Level } 2 \\
\end{array}$} & \multicolumn{3}{|c|}{$\begin{array}{l}\text { Nível } 3 \\
\text { Level } 3 \\
\end{array}$} \\
\hline & \multicolumn{3}{|c|}{5} & \multicolumn{3}{|c|}{8} & \multicolumn{3}{|c|}{19} \\
\hline & \multicolumn{3}{|c|}{10.650} & \multicolumn{3}{|c|}{25.374} & \multicolumn{3}{|c|}{91.234} \\
\hline & Lei $^{1}$ & Mcal & $\%$ cal & Lei & Mcal & $\%$ cal & Lei & Mcal & $\%$ cal \\
\hline Man. $^{2}$ & - & 13.447 & 65 & - & 23.024 & 57 & - & 54.714 & 48 \\
\hline$\% \mathrm{G}_{3,1} \%$ & 3,10 & 3.067 & 15 & 3,10 & 7.307 & 18 & 3,10 & 26.274 & 22 \\
\hline$\% \mathrm{G}_{>3,1} \%$ & 0,41 & 409 & 2 & 0,45 & 1.059 & 3 & 0,46 & 3.876 & 3 \\
\hline$\% \mathrm{P}_{2,85} \%$ & 2,85 & 1.660 & 8 & 2,85 & 3.956 & 10 & 2,85 & 14.223 & 12 \\
\hline$\% \mathrm{P}_{>2,85} \%$ & 0,27 & 155 & 1 & 0,25 & 346 & 1 & 0,24 & 1.232 & 1 \\
\hline $\mathrm{V}^{3}$ & 93,37 & 1.947 & 9 & 93,35 & 4.640 & 11 & 93,35 & 16.685 & 14 \\
\hline Total & 100,00 & 20.685 & 100 & 100,00 & 40.332 & 100 & 100,00 & 117.004 & 100 \\
\hline
\end{tabular}

1 Porcentagem na composição do leite (Milk composition percentage).

2 Manutenção do animal em lactação (Milking maintenance).

3 Veículo $=$ Lactose $(4,63 \%)+$ água + minerais $($ Carrier $=$ Lactose $[4.63 \%]+$ water + minerals $)$.

de produção, utilizando um programa de pagamento por qualidade implantado por uma empresa laticinista do Rio Grande do Sul.

\section{Resultados e Discussão}

O estudo dos dados gerados a partir das propriedades participantes do Programa de Pagamento por Qualidade forneceu os resultados a seguir apresentados.

O número médio de vacas em lactação, dentro dos níveis de produção, foi estimado pelas equações de regressão a partir da produção de leite média anual dentro de cada nível (Tabela 5). Observa-se que a maior escala de produção está relacionada aos melhores índices produtivos, provavelmente, em razão da especialização do produtor, que tem na atividade leiteira uma importante fonte de renda, disponibilizando maiores recursos para investimento na produção.

A maior produção por animal está condicionada ao material genético, entretanto as condições de ambiente são muito importantes para o bom desempenho animal. A maior escala de produção estimula o produtor a investir na melhoria das condições ambientais ofertadas aos animais, elevando o nível tecnológico da propriedade refletindo na maior produção por animal.

Aumento da produção por unidade animal, quando em pequena escala, acarreta acréscimo dos cus-
Tabela 5 - Estimativa do número médio de vacas em lactação, produção média de leite por vaca e produção média anual por propriedade, de acordo com os níveis de produção

Table 5 - Estimate of the average number of milking cows, medium production of milk by cow and annual medium production by property, according to the production levels

\begin{tabular}{|c|c|c|c|}
\hline $\begin{array}{l}\text { Níveis } \\
\text { Levels }\end{array}$ & $\begin{array}{c}\text { № de vacas } \\
\text { emlactação } \\
\text { N. of milking } \\
\text { cows }\end{array}$ & $\begin{array}{c}\text { Produção/vaca } \\
\text { (L/vaca/ano) } \\
\text { Production/cow } \\
\text { (L/cow/year) }\end{array}$ & $\begin{array}{l}\text { Produção anual } \\
\text { (L/ano) } \\
\text { Annual production } \\
\text { (L/year) }\end{array}$ \\
\hline 1 & 5 & 2.259 & 10.650 \\
\hline 2 & 8 & 3.144 & 25.374 \\
\hline 3 & 19 & 4.757 & 91.234 \\
\hline
\end{tabular}

tos de produção por unidade de produto, levando à redução das margens de lucro, tornando-se inviável economicamente para produtores de pequena escala.

Foram estimadas as receitas geradas por cada um dos componentes de qualidade do leite, segundo o Programa de Pagamento por Qualidade (Tabela 6).

A receita para os componentes do leite variou em função dos diferentes percentuais de bonificação dados aos diferentes níveis de produção, de acordo com o volume de leite entregue mensalmente. Neste programa, a remuneração é condicionada aos teores dos componentes presentes no leite, oferecendo 
bonificação como prêmio por ter alcançado os teores mínimos. Entretanto, não há diferenciação no valor de remuneração para qualquer um dos componentes, como valorização de um ou mais componentes de interesse da indústria.

Dessa forma, observa-se que, para o produtor, a receita é decorrente do volume de leite entregue, mantendo os teores mínimos determinados pela indústria. O maior valor de receita foi para o veículo, também responsável pela maior diferença entre os níveis de produção; enquanto a diferença de receita entre os níveis 1 e 3, para \%G e \%P (R \$0,0009 e $\mathrm{R} \$ 0,0007$, respectivamente), foi de $\mathrm{R} \$ 0,0224$.

O nível 1 apresentou custo mais elevado para produção de um litro de leite, enquanto os níveis 2 e 3 tiveram os menores custos (Tabela 7).

Os custos estão condicionados ao sistema de produção, segundo a classificação adotada por Krug (2001). O sistema extensivo praticamente não necessita de desembolso de capital, proporcionando o máximo de retorno por unidade de capital investido, ao passo que os sistemas intensivos necessitam de

Tabela 6 - Receita dos componentes $(\mathrm{R} \$)$, para cada 1 litro de leite, dentro dos respectivos níveis de produção

Table 6 - Revenue of the components $(R \$)$, for each liter of milk, by different production levels

\begin{tabular}{llll}
\hline $\begin{array}{l}\text { Característica } \\
\text { Characteristic }\end{array}$ & $\begin{array}{r}\text { Nível 1 } \\
\text { Level 1 }\end{array}$ & $\begin{array}{c}\text { Nível 2 } \\
\text { Level 2 }\end{array}$ & $\begin{array}{c}\text { Nível 3 } \\
\text { Level 3 }\end{array}$ \\
\hline$\% \mathrm{G}$ & 0,0142 & 0,0145 & 0,0151 \\
$\% \mathrm{P}$ & 0,0133 & 0,0135 & 0,0140 \\
$\mathrm{~V}$ & 0,1998 & 0,2072 & 0,2222 \\
Total & 0,2273 & 0,2352 & 0,2513 \\
\hline
\end{tabular}

$\% \mathrm{G}=$ Porcentagem de gordura $(\% F=$ Fat percentage $)$.

$\% \mathrm{P}=$ Porcentagem de proteína $(\% \mathrm{P}=$ Protein percentage $)$.

$\mathrm{V}=$ Veículo $(V=$ Carrier $)$.

Tabela 7 - Estimativa de custo variável $(R \$)$ para a produção anual e para a produção de um litro de leite

Table 7 - Estimate of variable cost $(R \$)$ for annual production and for the production of one liter of milk

\begin{tabular}{lccc}
\hline $\begin{array}{l}\text { Níveis } \\
\text { Levels }\end{array}$ & $\begin{array}{c}\text { Produção anual } \\
\text { L/ano } \\
\text { Annualproduction } \\
\text { L/year }\end{array}$ & $\begin{array}{c}\text { CustoR\$ } \\
\text { CostR\$ }\end{array}$ & $\begin{array}{c}\text { Custo/LitroR\$ } \\
\text { Cost/LiterR } \$\end{array}$ \\
\hline 1 & 10.650 & $1.854,33$ & \\
2 & 25.374 & $2.606,69$ & 0,1741 \\
3 & 91.234 & $10.108,70$ & 0,1027 \\
\hline
\end{tabular}

R. Bras. Zootec., v.33, n.6, p.2256-2265, 2004 (Supl. 3) investimento, independentemente se for a pasto, de semiconfinamento ou confinamento. Dessa forma, a viabilidade econômica da atividade estará condicionada à eficiência produtiva por animal ou por unidade de área.

A maior escala de produção, em função de maior número de animais em lactação, provoca diluição de custos com alimentação, principalmente os custos inerentes à implantação e manutenção de pastagens. Entretanto, o índice produtivo dos animais é um fator de relevante importância para eficiência econômica dos sistemas a pasto e semiconfinados (Tabela 7).

Da mesma forma, a viabilidade econômica do sistema de confinamento está condicionada à maior escala de produção, dependente do número de animais em lactação e de maior produtividade por animal. Entretanto, Holanda Jr. \& Madalena (1998) observaram que os melhores índices de produção por vaca não se refletiram necessariamente em maior rentabilidade, quando os índices produtivos estavam associados a incrementos de custos não compensatórios, necessitando de altos custos de instalações e alimentação.

Os resultados obtidos dentro dos níveis de produção, relacionados à tecnologia e ao investimento do produtor, corroboram os obtidos por Konzen (1998), que observou que os produtores que antecipam as inovações tecnológicas e expansão dos empreendimentos tendem a elevar seus ganhos, com a redução dos custos por unidade de produto, obtendo maior margem de retorno do fator capital investido.

Foram observadas diferenças entre os níveis de produção quanto ao custo dos componentes para cada litro de leite (Tabela 8). Verifica-se que os componentes (\%G, \% P e V) apresentaram custos mais elevados no nível 1 de produção e menores no nível 2. O resultado do nível 2 expressa maior eficiência dos investimentos com relação à alimentação dos animais, corroborando os resultados apresentados por Vilela et al. (1996), em que a produção de vacas em pastejo, embora inferior ao de vacas confinadas, apresentou custo operacional inferior, compensando a menor produção de leite a pasto. Embora o custo total de produção deste nível tenha sido maior que o do nível 1 , o custo por unidade de produto foi menor, concordando com os resultados relatados pela OCEPAR, citada por Konzen (1998), em que os níveis mais elevados de produção tenderam a aumentar a rentabilidade do produtor.

No nível 3, os custos para produção dos componen- 
tes do leite $(\% \mathrm{G}, \% \mathrm{P}$ e $\mathrm{V})$ foram intermediários em relação aos outros dois níveis, graças aos custos de investimento em tecnologia, para produção em escala, não significando que o produtor esteja tendo prejuízo. O seu rendimento poderá estar no valor agregado pela maior escala de produção de leite.

Os resultados obtidos a partir da função de lucro dos componentes do leite dentro dos respectivos níveis de produção estão expressos na Tabela 9. A gordura e a proteína apresentaram lucro negativo nos níveis 1 e 3 , em função da baixa remuneração e do alto custo com energia para produção desses componentes. No nível 2, a proteína obteve valor de lucro positivo e maior valor para a gordura em relação aos níveis 1 e 3, apesar de negativo.

O veículo teve lucro positivo em todos os níveis devido aos custos para produção de uma unidade de veículo estarem condicionados a produção de lactose, a qual demanda menor requerimento de energia para sua síntese.

O componente da função de lucro determinante desse resultado foi o custo de produção estimado para os componentes, onde a gordura que possui o maior requerimento de calorias para sua síntese, teve o resultado de lucro mais negativo. Isto ocorreu porque o preço pago por unidade dos componentes não possui a mesma relação do custo para síntese dos mesmos.

Os valores econômicos estimados para os componentes do leite estão apresentados na Tabela 10. Estes valores foram obtidos a partir da função de lucro para cada unidade do componente, neste caso, um litro.

Observa-se que a gordura e a proteína tiveram valor econômico negativo em todos os níveis, sendo que o nível 1 teve o pior resultado e maior valor negativo, para ambos os componentes.

Tabela 8 - Custo dos componentes $(R \$)$, para cada 1 litro de leite, de acordo com os respectivos níveis de produção

Table 8 - Cost of the components $(R \$)$, for each liter of milk, by production levels

\begin{tabular}{lccc}
\hline $\begin{array}{l}\text { Característica } \\
\text { Characteristic }\end{array}$ & $\begin{array}{c}\text { Nível 1 } \\
\text { Level 1 }\end{array}$ & $\begin{array}{c}\text { Nível 2 } \\
\text { Level 2 }\end{array}$ & $\begin{array}{c}\text { Nível 3 } \\
\text { Level 3 }\end{array}$ \\
\hline$\% \mathrm{G}(\% F)$ & 0,0293 & 0,0213 & 0,0286 \\
$\% \mathrm{P}$ & 0,0153 & 0,0110 & 0,0146 \\
$\mathrm{~V}$ & 0,0164 & 0,0118 & 0,0158
\end{tabular}

$\% \mathrm{G}=$ Porcentagem de gordura (\% $\mathrm{F}=$ Fat percentage $)$.

$\% \mathrm{P}=$ Porcentagem de proteína $(\% \mathrm{P}=$ Protein percentage $)$.

$\mathrm{V}=$ Veículo $(V=$ Carrier $)$.
Estes resultados indicam que o produtor está tendo prejuízo para produzir os componentes gordura e proteína, pois a remuneração não é suficiente para cobrir os custos de produção dos mesmos.

O nível de produção influenciou significativamente os resultados dos valores econômicos. O valor econômico da gordura no nível 1 foi 2,25 vezes menor que no nível 2 e 1,13 vezes menor que no nível 3 de produção, comprovando que o nível mais baixo apresenta maior prejuízo na produção de gordura e o nível 2, os melhores resultados, porém ainda negativos para produção desse componente.

O valor econômico para a proteína no nível 1 foi 3,23 vezes menor que no nível 3, enquanto no nível 2 obteve-se valor econômico positivo.

O nível 2 de produção foi o que apresentou melhores resultados para todos os componentes, em virtude do menor custo de produção dos mesmos, mas tende a apresentar redução dos teores de gordura, em razão do seu valor negativo.

O veículo (V) apresentou valor econômico positivo em todos os níveis de produção e sempre superior ao valor econômico dos outros componentes. Estes resultados estimulam o aumento da produção de volume de leite e diminuição dos sólidos, no caso gordura e proteína, nos níveis 1 e 3, posto que a produção destes componentes gera prejuízo ao produtor. No nível 2, o valor negativo para gordura estimula sua redução e, para a proteína, embora com valor positivo, é inferior ao do veículo. Dessa forma, o componente de maior importância econômica nesta análise foi o veículo. Esta tendência também foi observada em estudos realizados por Madalena (1999a), ao analisar o sistema de pagamento utilizado por uma cooperativa no Estado de Minas Gerais e por Vercesi Filho et al. (2001), ao avaliarem uma propriedade no Estado de Minas Gerais.

Tabela 9 - Valores (R\$) obtidos a partir da função de lucro dos componentes para cada litro de leite de acordo com os níveis de produção

Table 9 - Values $(R \$)$ obtained from the function of profit of the components for each liter of milk by production levels

\begin{tabular}{lccc}
\hline Característica & Nível 1 & Nível 2 & Nível 3 \\
Characteristic & Level 1 & Level 2 & Level 3 \\
\hline$\% \mathrm{G}(\% F)$ & $-0,0151$ & $-0,0068$ & $-0,0134$ \\
$\% \mathrm{P}$ & $-0,0019$ & 0,0026 & $-0,0006$ \\
$\mathrm{~V}$ & 0,1834 & 0,1954 & 0,2064 \\
\hline
\end{tabular}

$\% G=$ Porcentagem de gordura $(\% F=$ Fat percentage $)$.

$\% \mathrm{P}=$ Porcentagem de proteína $(\% \mathrm{P}=$ Protein percentage $)$.

$\mathrm{V}=$ Veículo $(V=$ Carrier $)$. 
Tabela 10 - Determinação dos valores econômicos para cada unidade dos componentes do leite de acordo com os níveis de produção

Table 10 - Determination of the economic values for each unit of milk components by production levels

\begin{tabular}{lccc}
\hline $\begin{array}{l}\text { Característica } \\
\text { Characteristic }\end{array}$ & $\begin{array}{c}\text { Nível 1 } \\
\text { Level 1 }\end{array}$ & $\begin{array}{c}\text { Nível 2 } \\
\text { Level 2 }\end{array}$ & $\begin{array}{c}\text { Nível 3 } \\
\text { Level 3 }\end{array}$ \\
\hline $\mathrm{G}(1 \mathrm{~L})$ & $-0,4290$ & $-0,1906$ & $-0,3772$ \\
$F(1 \mathrm{~L})$ & & & \\
$\mathrm{P}(1 \mathrm{~L})$ & $-0,0624$ & 0,0836 & $-0,0193$ \\
$P(1 \mathrm{~L})$ & 0,1964 & 0,2093 & 0,2210 \\
$\mathrm{~V}(1 \mathrm{~L})$ & & & \\
$V(1 \mathrm{~L})$ & & & \\
\hline
\end{tabular}

O sistema de pagamento estudado não está cobrindo os custos de produção dos componentes sólidos do leite, levando à tendência de redução na produção de gordura e de proteína, em decorrência da baixa remuneração. Esta tendência provocará prejuízos também à indústria que depende dos teores dos sólidos para produção dos derivados lácteos. O Programa de Pagamento por Qualidade estudado não está sendo suficientemente eficiente na indução de aumento na produção de sólidos, principalmente a proteína, de acordo com tendência mundial, conforme relatam Oldenbroek \& Brascamp (1994), na Holanda, e Spelman \& Garrick (1997), na Nova Zelândia, dois grande produtores mundiais de leite.

\section{Conclusões}

Os diferentes níveis de produção geram diferentes custos de produção por unidade de produto, influenciando o valor econômico das características.

O Programa de Pagamento por Qualidade estudado gera maior valor econômico para o veículo, valor econômico negativo para gordura nos três níveis de produção e valor positivo para proteína no nível 2.

Os valores econômicos obtidos favorecem os produtores que produzirem menores teores de gordura e de proteína, contrariando a tendência mundial da atividade leiteira.

Estudos mais aprofundados devem ser desenvolvidos visando a implantação de adequado programa de remuneração aos componentes sólidos, visando o estímulo do aumento dos seus teores na composição do leite, de forma economicamente viável ao produtor.

\section{Literatura Citada}

BEKMAN, H.; Van ARENDONK, J.A.M. Derivation of economic values for veal, beef and milk production traits using profit equations. Livestock Production Science, v. 34, n.1, p.35-56, 1993.

BOWMAN, P.J.; VISSCHER, P.M.; GODDARD, M.E. Customized selection indices for dairy bulls in Australia. Animal Science, v.62, n.2, p.393-403, 1996.

BUZINHANI, O.S. Porque pagamos pela proteína e pelo leite higiênico. In: SIMPÓSIO NACIONAL DE MELHORAMENTO ANIMAL, 2., 1998, Uberaba. Anais... Uberaba: Sociedade Brasileira de Melhoramento Animal, 1998. p.127-130.

DEKKERS, J.C.M.; GIBSON, J.P. Applying breeding objectives to dairy cattle improvement. Journal of Dairy Science, v.81, n.2, p.19-35, 1998.

DÜRR, J.W.; RORATO, P.R.N. Seleção para a qualidade e composição do leite. Palavras e atitudes. In: Simpósio Nacional de Melhoramento Animal. 3., 2000, Belo Horizonte. Anais... Belo Horizonte: Sociedade Brasileira de Melhoramento Animal, 2000. p.237-247.

DÜRR, J.W. Comunicação pessoal, 2001.

EMBRAPA. Centro Nacional de Pesquisa de Gado de Leite, Juiz de Fora, 2001. Disponível em:<http:// www.cnpgl.embrapa.br/producao/02producao/tabela02.03. html> Acesso em: 15 nov. $2001 \mathrm{a}$.

. Centro Nacional de Pesquisa de Gado de Leite, Juiz de Fora, 2001. Disponível em:<http:// www.cnpgl.embrapa.br/producao/02producao/tabela02.18. html> Acesso em: 15 nov. 2001 b.

GRÖEN, A.F. Economic values in cattle breeding. I. Influences of production circumstances in situations without output limitations. Livestock Production Science, v.22, p.1-16, 1989.

GURGEL, A.C.; SANTOS, F.A.A.; TEIXEIRA, E.C. Relações de produção na pecuária leiteira de Minas Gerais - 1995. Revista de Economia e Sociologia Rural, v.38, n.4, p.29-51, 2000.

HAZEL, L.N. The genetic basis for constructing selection indexes. Genetics, n.28, p.476-490, 1943.

HOLANDA JR., E.V.; MADALENA, F.E. Rentabilidade de diferentes sistemas de produção deleite na região Sudeste. In: SIMPÓSIO NACIONAL DE MELHORAMENTO ANIMAL, 2., 1998, Uberaba. Anais... Uberaba: Sociedade Brasileira de Melhoramento Animal, 1998. p.113-120.

KONZEN, O.G. Modernização e competitividade entre sistemas na produção de leite. Revista de Economia e Sociologia Rural, v.36, n.1, p.105-125, 1998.

KRUG, E.E.B. Sistemas de produção de leite: identificação de benchmarking. Porto Alegre: Pallotti, 2001. 256p.

MADALENA, F.E. Valores econômicos para a seleção de gordura e proteína do leite. Revista Brasileira de Zootecnia, v.29, n.3, p.678-684, 1999a.

MADALENA, F.E. Conseqüências econômicas da seleção para gordura e proteína do leite no Brasil. Revista da Sociedade Brasileira de Zootecnia, v.29, n.3, p.685-692, 1999 b.

MANCIO, A.B.; SCHIFFLER, E.A.; LONDOÑO HERNÁNDEZ, F.I. Eficiência técnica e econômica de quatro empresas de produção de leite da região de São Carlos, SP. Arquivo Brasileiro de Medicina Veterinária e Zootecnia, v.51, n.3, p.283-286, 1999. 
MOAV, R.; HILL, W.G. Specialized sire and dam lines. IV. Selection within lines. Animal Production, v.8, p.375-390, 1966.

NATIONAL RESEARCH COUNCIL - NRC. Nutrient requirements of dairy cattle. 7.ed. Washington, D.C.: National Academy Press, 2001. 408p.

OLDENBROEK, J.K.; BRASCAMP, E.W. Breeding goal for milk composition. In: WORLD CONGRESS ON GENETICS APPLIED TO LIVESTOCK PRODUCTIONS, 1994, Guelph. Proceedings... Guelph, n.18, p.224-226, 1994.

PEARSON, R.E.; MILLER, R.H. Economic definition of total performance breeding goals and breeding values for dairy cattle. Journal of Dairy Science, v.64, n.2, p.857-869, 1981.

RORATO, P.R.N.; VERNEQUE, R.S.; MARTINEZ, M.L. et al. Interação genótipo-ambiente para a produção de leite em rebanhos da raça holandesa no Brasil. (I) modelo de touro. Ciência Rural, v.29, n.4, p.717-720, 1999.

STATISTICAL ANALYSIS SYSTEM - SAS. User's guide: Basic and statistic. 5.ed. Cary: 1996. 1290p.

SMITH, C. Effects of changes in economic weights on the efficiency of index selection. Journal of Animal Science, v.56, n.3, p.1057-1064, 1983.
SPELMAN, R.J.; GARRICK, D.J. Effect of live weight and differing economic values on responses to selection for milk fat, protein, volume, and live weight. Journal of Dairy Science, v.80, n.10, p.2557-2562, 1997.

VEERKAMP, R.F. Selection for economic efficiency of dairy cattle using information on live weight and feed intake: a Review. Journal of Dairy Science, v.81, n.1, p.1109-1119, 1998.

VERCESI FILHO, A.E.; MADALENA, F.E.; FERREIRA, J.J. et al. Pesos econômicos para seleção de gado de leite. Revista Brasileira de Zootecnia, v.29, n.1, p.145-152, 2000.

VILELA, D.; ALVIM, M.J.; CAMPOS, O.F. et al. Produção de leite de vacas holandesas em confinamento ou em pastagem de coast-cross. Revista da Sociedade Brasileira de Zootecnia, v.25, n.6, p.1228-1244, 1996.

Recebido em: 09/07/02

Aceito em: 29/03/04 